\title{
Rehabilitation Needs of Persons with Schizophrenia and their Families
}

Pavithra S Raghava* , Niveditha $S^{\dagger}$ and Dharitri R $\ddagger$

\begin{abstract}
Schizophrenia, a major mental illness, is associated with disability in almost all areas of living. A psychosocial rehabilitation programme that comprehensively addresses the needs felt by users is essential for the management of this disability. This paper aims at giving insights about the perceived rehabilitation needs of persons with schizophrenia and their primary caregivers. The sample consisted of 30 out-patients diagnosed with Schizophrenia (ICD-10 criteria), and their respective caregivers (30 in number). Perceived rehabilitation needs were assessed using the Rehabilitation Needs Assessment Schedule (Nagaswami et al, 1985). The major needs identified by patients as well as caregivers were attitude modification, employment, and help for the family. Additionally, caregivers expressed a need for skills training and options for leisure time engagement for their wards. These findings have implications for planning psychosocial rehabilitation programmes.
\end{abstract}

* Former Postgraduate Student of Psychosocial Rehabilitation, Richmond Fellowship Post Graduate College for Psychosocial Rehabilitation, Bangalore;pavithra.raghava@gmail.com

† Assistant Professor, Richmond Fellowship Post Graduate College for Psychosocial Rehabilitation, Bangalore; niveditha.sekhar@gmail.com

‡ Associate Professor, Richmond Fellowship Post Graduate College for Psychosocial Rehabilitation, Bangalore; dharitri_r@yahoo.co.in 
Keywords: Schizophrenia, Rehabilitation, Rehabilitation needs, Users, Families

\section{Introduction}

Schizophrenia is a prototype of severe mental illness characterized by marked distortion of reality, thinking, perception and emotion, there may also be associated social withdrawal and display of bizarre behavior. Being a chronic illness, it results in significant dysfunction due to disability, subjective distress due to symptoms and consequent burden on the family. Schizophrenia is an enigmatic, tragic disease, and perhaps the most devastating of mental illnessess. It strikes an individual in his/her most productive life period and affects all aspects of the individual's life, preventing the person from leading a full normal life - attending school/college, being employed, having a close network of friends, marrying and having children (Hales, Yudofsky and Talbott, 2001). Because of its complexity, high rate of incidence and its tendency to recur or become chronic, schizophrenia is considered the most serious of all mental disorders, as well as the most baffling (Carson, Butcher, and Mineka, 1998).

Although neuroleptic medication has remained the mainstay of treatment in schizophrenia, a significant proportion do not show any change in their clinical condition despite medication. The heterogeneous nature of this illness makes treatment with neuroleptics alone inadequate. Kern, Glynn, Horan, and Marder (2009) note that medications alone are not sufficient for recovery and adaptive adjustment; psychosocial treatments are necessary complements to achieve functional recovery.

Psychosocial rehabilitation is defined as a process of enabling a person to renew old skills and acquire new skills that will qualify him/her to live in the general society to the greatest extent his particular condition and circumstances will allow (Glasscote, Cumming, Rutman, Susses and Glassman, 1971). A psychosocial rehabilitation plan should be in tune with the needs of the patient and caregiver. These needs can be wide and varied. Needs are the requirements of individuals to enable them to achieve, maintain or 
restore an acceptable level of social independence or quality of life (Health Social Service Inspectorate, 1991).

No psychiatric treatment facility can lay any claim to completeness, without an adequate aftercare and rehabilitation unit to meet the needs of chronically mentally ill persons (Nagaswami, Valecha, Thara, Rajkumar, and Menon, 1985). As clients with different psychiatric disabilities, different problems, different duration and chronicity of illness seek rehabilitation, their needs are very different. For an effective rehabilitation program comprehensive assessment of needs should ideally be the starting point in the development of treatment plan for an individual. This can be used periodically in monitoring the efficacy of the program. Therefore, the assessment and evaluation of needs has been put forth as an important dimension in the development, monitoring and evaluation of comprehensive psychiatric service (Hansson, Bjorkman, and Sevnsson, 1995).

Involvement of patients as well as their families is one of the basic principles of rehabilitation. Understanding the needs of patients and their families in the context of rehabilitation plan becomes the starting point.

Nagaswami et al. (1985) in their study on the rehabilitation needs of 59 persons with schizophrenia using a Rehabilitation Needs Assessment Interview Schedule, found $80 \%$ of them having some need or the other in the context of rehabilitation plan. High need was expressed in the area of employment followed by help for the family. Very few expressed need related to accommodation. Men and women did not differ significantly as far as their rehabilitation needs were concerned.

A study on the needs of care among the relatives of long-term users of day care was conducted by McCarthy, Prettyman, and Friedman (1995). Using the Camberwell Family Interview and MRC (Minnesota Research Center) Social Behavior Schedule, they found that problems occurred most frequently in the area of information and advice, emotional support and respite holiday care. It was in these three areas that the rate of unmet needs was highest. 
Caregivers reported need for help and support in carrying out personal and domestic tasks such as dressing or housekeeping.

Winefield and Harvey (1994) carried out a study on the needs of family caregivers of persons with schizophrenia for a duration of 14 years . 121 caregivers responded to the questions. Need for easy access to treatment, need for rehabilitation and social adjustment, need for practical help for the caregivers such as transport, household help and professional help such as counseling and intervention during psychotic episodes were some of the important needs expressed. Regarding accommodation, nearly half of the caregivers preferred that the patients live in supervised accommodation. These were the patients who had difficulty in self-care and communication skills, and were more turbulent.

A study on the perceived needs of mental health care was undertaken by Meadows, Burgess, Bobevski, Fossey, Harvey, and Liaw (2002). The study focused on determining the influence of diagnosis, demography and disability on the perceived needs of mental health care. The community based survey included 10,641 Austrians who were evaluated using a computerized field questionnaire. The report revealed that women had higher rates of perceived needs for mental health care than men, and that age had a significant influence on overall perceived needs and also on specific needs. Patients above the age of 45 years perceived more needs than patients in the younger age group. Younger adults had lower rates of perceived needs for medication and counseling and older adults had less perceived need for information, counseling, social intervention and skills training.

Ochoa, Haro, Autonell, Pendas, Teba, and Marquez (2003) set out to identify the common needs of persons with schizophrenia and compared them with the perception of these needs by the staff. They evaluated 231 out-patients with schizophrenia using Camberwell Assessment of Needs Schedule. The study revealed that the staff detected more met and unmet needs than patients did.

Studies pertaining to needs of persons with chronic mental illness have revealed high need in the area of occupation and employment in India, the least need for accommodation. However, felt and 
perceived needs of the families and caregivers are equally important and critical as that would have an impact on the outcome of a psychosocial rehabilitation plan. Considering this it is important to understand the needs of families and caregivers in the context of the rehabilitation plans for the ill person. The present study attempted to address this aspect.

\section{Materials and methods}

The present study aimed at assessing and comparing the rehabilitation needs of persons with schizophrenia and their families/caregivers. The study adopted a descriptive design. A Purposive sample was drawn from an out-patient department from a private psychiatric service center in Bangalore after taking permission from the Director of the center. The study population comprised of persons with a diagnosis of schizophrenia as per ICD10. All cases attending the outpatient services of the center during the period of study and who met the inclusion criteria were considered for the study. For the patient group, persons with a diagnosis of schizophrenia as per ICD-10, with no co-morbid condition and with no active psychopathology at the time of the study were considered. Only those availing treatment at the psychiatric facility as out-patients and who had the illness for more than 2 years were considered for inclusion in the study. For the caregiver group, the primary caregivers of the patients from their respective family were considered for the study. The final sample for the study comprised of 60 respondents, of whom 30 were persons with schizophrenia and 30 were their respective caregivers (family members).

\section{Tools}

- Socio-demographic Data Form

- Rehabilitation Needs Assessment Schedule (Nagaswami et al., 1985) - This tool collects qualitative information and does not require any observer rating. The tool contains open ended questions that cover the following areas:

1. Occupation and employment 
2. Accommodation

3. Leisure

4. Psycho-social attitude modification

5. Help for the family

6. Skills training

7. Other help not covered by the above.

\section{Procedure}

Potential respondents, who fulfilled the criteria for inclusion in the study, were explained about the purpose of the study and those who were willing to participate were included as respondents. Informed written consent was obtained from the willing participants. After gathering the socio-demographic details, the researcher administered the Rehabilitation Needs Assessment Schedule to the participants individually.

The different needs indicated by the participants comprised of multiple responses. These responses were assigned numeric values, and these were taken as scores of each respondent for that domain.

\section{Results}

\section{Socio-demographic profile of the participants}

There were equal number of men and women patients (15 each) in the study, and 17 female and 13 male caregivers. Over half of the patients $(53.3 \%)$ were under 35 years of age; $60 \%$ of the caregivers were aged 45 years or more. $70 \%$ of patients and caregivers hailed from urban areas, $23.3 \%$ were from semi-urban areas, and a small minority of $6.7 \%$ belonged to rural areas. Most of the patients and the caregivers had a minimum of school education; some of them ( $30 \%$ of caregivers and $16.7 \%$ of the patient group) had completed their bachelor's degree.

With regard to occupational status, most of the caregivers $(46.7 \%)$ were housewives; some $(13.3 \%)$ had retired from employment; 
while some $(13.3 \%)$ were engaged in agricultural activities. In the patients' group $33.3 \%$ were unemployed, $20 \%$ were housewives, $16.7 \%$ were working in some industrial sector, $13.3 \%$ were engaged in agricultural activities and 10\% were students. As for the marital status of the patient group $43.3 \%$ of them remained married, $43.3 \%$ were single, $6.7 \%$ were divorcees and $6.7 \%$ had separated from their spouse.

$80 \%$ of patients reported a monthly income of less than Rs. 2,000/ while over half $(56.7 \%)$ of the caregivers reported their monthly income to be below Rs. 15,000/-. Half of the caregivers (50\%) were parents of the patient, a little over one-third (36.6\%) were spouses.

With regard to duration of illness, nearly half of the patients $(46.6 \%)$ had been ill for under 5 years, one-third (33.4\%) between 6 to 13 years and one-fifth $(20 \%)$ were ill for 14 years or more.

\section{Rehabilitation Needs profile}

Table 1. Rehabilitation needs of patients and caregivers

\begin{tabular}{|l|c|c|c|c|}
\hline \multirow{2}{*}{\multicolumn{1}{|c|}{ Need domains }} & \multicolumn{2}{c|}{ Patients } & \multicolumn{2}{c|}{ Caregivers } \\
\cline { 2 - 5 } & $\mathrm{N}=30$ & $\%$ & $\mathrm{~N}=30$ & $\%$ \\
\hline Help needed (overall needs) & 27 & 90.0 & 28 & 93.3 \\
\hline Employment & 11 & 36.7 & 16 & 53.3 \\
\hline Accommodation & 1 & 3.3 & 9 & 30.0 \\
\hline Psychosocial attitude modification & 24 & 80.0 & 23 & 76.7 \\
\hline Help for the family & 8 & 26.7 & 19 & 63.3 \\
\hline Skills training & 7 & 23.3 & 21 & 70.0 \\
\hline Leisure & 0 & 0.0 & 12 & 40.0 \\
\hline Total & 30 & 100.0 & 30 & 100.0 \\
\hline
\end{tabular}

$\chi_{\mathrm{r}}^{2}=8.571 ; \mathrm{P}=>0.05$ (Needs comprise of multiple responses)

In the present study, rehabilitation needs on all domains were indicated more by caregivers than patients. Both the groups indicated needs in the area of psychosocial attitude modification ( $80 \%$ of patients and $76.7 \%$ of caregivers). There were differences in how other needs were perceived by each group. Patients identified employment $(36.7 \%)$, help for the family $(26.7 \%)$, and skills training $(23.3 \%)$ as other important needs, while caregivers identified skills training $(70 \%)$, and help for the family $(63.3 \%)$ more than 
employment $(53.3 \%)$. Leisure time management was a need that patients did not identify, while $40 \%$ of caregivers felt this was an important need. Need for accommodation was another need that caregivers (30\%) identified but not patients.

Several socio-demographic variables were found to influence rehabilitation needs significantly. Age, education, occupation, patient's monthly income, duration of illness, and relationship of primary caregiver were significantly related to the rehabilitation needs that patients indicated. On the other hand, for caregiver's age, domicile, educational level, and occupation were significantly related to the rehabilitation needs they indicated for their wards. These are summarized in Table 2.

Table 2. Socio-demographic variables significantly related to rehabilitation needs

\begin{tabular}{|l|c|c|c|c|}
\hline \multirow{2}{*}{ Socio-demographic variables } & \multicolumn{2}{|c|}{ Patients } & \multicolumn{2}{c|}{ Caregivers } \\
\cline { 2 - 5 } & $\chi_{\mathrm{r}}^{2}$ & $\mathrm{P}$ & $\chi_{\mathrm{r}}^{2}$ & $\mathrm{P}$ \\
\hline Age & 13.66 & $<0.01$ & 18.13 & $<0.01$ \\
\hline Domicile & - & - & 13.23 & $<0.05$ \\
\hline Education & 17.37 & $<0.01$ & 11.26 & $<0.05$ \\
\hline Occupation & 29.82 & $<0.01$ & 11.21 & $<0.05$ \\
\hline $\begin{array}{l}\text { Income (patient's monthly } \\
\text { income) }\end{array}$ & 13.22 & $<0.05$ & - & - \\
\hline Duration of illness & 11.66 & $<0.05$ & - & - \\
\hline Relationship of primary caregiver & 20.85 & $<0.01$ & - & - \\
\hline
\end{tabular}

Younger patients identified higher employment needs, while older patients (over 55 years) reported the lowest. The overall perceived needs for their wards were greater among caregivers over 45 years of age, who indicated higher needs in all the six need domains as compared to caregivers from other age groups. Overall, women patients and women caregivers alike reported fewer needs than their male counterparts, but reported more needs than men with regard to employment.

Patients and caregivers from urban areas identified more needs that those from semi-urban and rural areas. For patients from urban and semi-urban areas, the major needs were psychosocial attitude modification and employment, while the needs of rural patients and caregivers were psychosocial attitude modification 
and help for the family. Urban caregivers perceived more needs in domains like skills training, employment, leisure and accommodation.

Psychosocial attitude modification and employment were major needs for patients who were single, while psychosocial attitude modification and help for the family were important for married patients. Patients with higher education (pre-university, degree and professional education) had more overall needs, especially with regard to employment. Across occupational groups for patients, psychosocial attitude modification was the most important need, but there were other differences between the groups - for instance, students and those in industrial jobs rated employment needs as important, while housewives and those practicing agriculture indicated help for their family. Psychosocial attitude modification was the most important need across caregiver groups.

Patients with lower incomes (less than Rs. 4,000/- per month) indicated employment need as important, but psychosocial attitude modification was rated high by patients irrespective of income. Caregivers from lower income groups had more needs for their wards with regard to employment and help for the family.

Patients with shorter duration of illness (less than 5 years) reported more needs. For those with shorter illness duration, employment and skills training were additionally important, while for the more chronic ill, need for assistance to the family was also identified. Need for employment was identified more when the caregiver was a parent, while caregivers who were spouses or siblings identified help for the family as an important need.

\section{Discussion}

The study revealed that $90 \%$ of patients and $93.3 \%$ of the caregivers expressed needs in at least one of the six areas. Nagaswami et al (1985), and Prafulla, Murthy \& Ramaprasad (2010) also report similar findings. Gandotra, Paul, Daniel, Kumar, Raj and Sujeetha (2001) also found that $73.3 \%$ of the out-patients had some kind of rehabilitation needs. Most of those patients indicated needs in the 
area of psychosocial attitude modification, all of which are consistent with the present study.

Majority of the patients group in the present study indicated needs in the area of psychosocial attitude modification (80\%) followed by employment (36.7\%). For caregivers too attitude modification was an important requirement $(76.7 \%)$ followed by need for skills training $(70 \%)$. However, earlier studies have reported high patient need for employment and help for family members (Nagaswami et al., 1985). This could possibly be due to the difference in the socioeconomic conditions of the sample studied. Attitude modification is a strong need across the group as stigmatization still prevails although considerable progress has been made in understanding and treating schizophrenia. Crisp et al (2000), in a survey found that schizophrenia elicited the most negative opinion and over $70 \%$ of those questioned thought that persons with schizophrenia were dangerous and unpredictable. Similar stigmatizing attitudes have been reported in recent Indian studies (Thara \& Srinivasan, 2000; Raguram, Raghu, Vounatsou and Weiss, 2004; Murthy, Shankar, Sharma, Shetty, Srivatsava, Thara and Wig, 2001; Thara, Kamath and Kumar, 2003 a \& b; Mallikarjuna, Murthy and Dharitri, 2006; Loganathan and Murthy, 2008; Kishore, Mukherjee, Parashar, Jiloha and Ingle, 2007, Prafulla et al., 2010) too.

Caregivers have indicated a dire need for skills training for their wards (70\%). Studies have reported that persons with schizophrenia need help and support for carrying out personal and domestic tasks and some need constant supervision. (McCarthy et al., 1995). Schizophrenia, very often causes loss of learned skill of daily living or, in case of early onset, may impede the learning of these skills. Hence, training in these skills becomes essential for adequate functioning.

Ralston, Beesley, and Bogue (1998) report that psycho-education about the illness, skills training (ADL and Social skills), communication skills and budgeting were the important needs expressed. This was in addition to specific needs for help in sexual problems, eating and alcohol problems. They concluded that such needs should be taken into account while planning rehabilitation programs. 
Caregivers (70\%) and patients (23.3\%) have indicated help for the family, in terms of financial support for the family, employment for other family members, education of children in the family and even marriage. This appears to reflect the social problems faced by the families. Prafulla et al (2010) and Nagaswami et al (1985) also report similar need in a different population.

Accommodation was however not a concern for the patient group $(3.3 \%)$. They expressed satisfaction with their living arrangements. This was similar to the findings of Pillai et al (2010) and Prafulla et al (2010). However, some caregivers (30\%) did indicate a need for separate accommodation for their wards either as a temporary arrangement or a long standing one. This differs from society to society due to cultural factors. Fostering interdependence is a hall mark of Indian society which envisages living together with the family. This is in contrast with other societies where fostering independence is important. Hence, need for accommodation is a serious/important concern (Winfield and Harvey, 1994; Hansson et al., 1995).

Caregivers above the age of 45 years indicated more needs for their wards when compared to other age groups. In all six areas they indicated higher needs for their wards as reported by Meadows et al (2002). Patient's functional deficits and worry about the patient's future are most often the cause of concern among caregivers (McCarthy et al., 1995). This concern and worry may lead them to perceive the need for overall support in all the areas to ensure some security.

Duration of illness of patients can affect their pattern of needs $\left(\mathrm{X}_{\mathrm{r}}=11.66, \mathrm{p}=<0.05\right)$. In the present study longer duration of illness was found to be associated with higher need for employment. Pillai et al. (2010) noted that finding help with employment was an important need identified by persons with schizophrenia in their study. However, Hansson et al. (1995) reported that patients with longer duration of illness (>4years) more often had needs in the area of finance.

Needs indicated by patients were significantly different depending on who their primary caregiver was $\left(\mathrm{X}_{\mathrm{r}}=20.85, \mathrm{p}=<0.01\right)$. Needs in 
the area of employment was higher when the primary caregiver was a parent. On the other hand patients felt more need for attitude change when their primary caregiver was their spouse or sibling.

\section{Conclusion}

The present research aimed at studying and comparing the perception of rehabilitation needs by persons with schizophrenia and their caregivers. The study revealed that patients and their caregivers do not differ significantly in their perception of rehabilitation needs. This study highlights the need for attitude change toward people with mental illness, especially among family members, and employment for the mentally ill persons. Support to the family is another important need expressed. Age, duration of illness and relationship with the ill person has a significant association with the perceived rehabilitation needs. Mental health services need to keep this in view and address these issues.

\section{References}

Carson, R. C., Butcher, J. N., \& Mineka, S. (1998). Abnormal psychology and modern life. $3^{\text {rd }}$ edition, Addison-Wesley Educational Publishers.

Crisp, A. H., Gelder, M. G., Rix, S., Meltzer H. I., \& Rowlands, O. J. (2000). Stigmatization of people with mental illness. British Journal of Psychiatry, 177 (1) 4-7.

Glasscote, M. R., Cumming, E., Rutman, I. D., Susses, S. M., \& Glassman, S. M. (1971). Rehabilitating the mentally ill in the community: A study of psychosocial rehabilitation needs. Washington DC: The Joint Information Service of the American Psychiatric Association and The National Association for Mental Health.

Gandotra, S., Paul, S. E., Daniel, M., Kumar, K., Raj, H. A., \& Sujeetha, B. (2004). A preliminary study of rehabilitation needs of in-patients with schizophrenia. Indian Journal of Psychiatry, 46(3), 244-255. doi: 10.4103/0019-5545.69229

Hales, R. E., Yudofsky, S. C., \& Talbott, J. A. (2001). Text book of psychiatry. $3^{\text {rd }}$ edition, New Delhi: Jaypee Brothers Medical Publishers.

Hansson, L., Bjorkman, T. \& Sevnsson, B. (1995). The assessment of needs in psychiatric patients: Inter-rater reliability of the Swedish version of 
Camberwell Assessment of Needs instrument and results from a cross-sectional study. Acta Psychiatrica Scaninavica, 92, 185-93.

Health Social Services Inspectorate: Care management and assessmentpractitioner's guide, HMSO: London.

Kern, R. S., Glynn, S. M., Horan, W. P. \& Marder, S. R. (2009). Psychosocial treatments to promote functional recovery in schizophrenia. Schizophrenia Bulletin, 35(2): 347-361 first published online January 27, 2009 doi:10.1093/schbul/sbn177. Accessed from

http:/ / schizophreniabulletin.oxfordjournals.org/content/early/2009/01 /27/schbul.sbn177.full

Kishore, J., Mukherjee, R., Parashar, M., Jiloha, R. C. \& Ingle, G. K. (2007). Beliefs and attitudes towards mental health among medical professionals in Delhi. Indian Journal of Community Medicine, 32 (3), DOI: 10.4103/0970-0218.36827 198-200.

Loganathan, S., \& Murthy, S. R. (2008). Experiences of stigma and discrimination endured by people suffering from schizophrenia. Indian Journal of Psychiatry, 50, 30-46. doi: 10.4103/0019-5545.39758.

McCarthy, J., Prettyman, R., \& Friedman, T. (1995). The stigma of psychiatric patient care. Psychiatric Bulletin, 19 (6), 349-351.

Mallikarjuna, S. H., Murthy, S. K. \& Dharitri, R. (1995). Orientation towards mental illness in a rural community. Unpublished M.Sc. dissertation, Rajiv Gandhi University of Health Sciences, Bangalore.

Meadows, G., Burgess, P., Bobevski, I., Fossey, E., Harvey, C., \& Liaw, S.T. (2002). Perceived needs for mental health care: Influence of diagnosis, demography and disability. Psychological Medicine, 32, 200-309.

Murthy, R. S., Shankar, R., Sharma, A., Shetty, H., Srivatsava, A., Thara, R. \& Wig, N. N. (2001). Stigma experiences of patients of schizophrenia illness and the family members from India. Unpublished data. In Murthy, S.R. Perspectives on the stigma of mental illness in Okasha, A. and Stefanis, C.N. (eds.). Stigma of mental illness in the third world. World Psychiatric Association, 2005.

Nagaswami, V., Valecha, V., Thara, R., Rajkumar, S. \& Menon, M. S. (1985). Rehabilitation Needs of Schizophrenia Patients. Indian Journal of Psychiatry, 27 (3), 213-20.

Ochoa, S., Haro, J. M., Autonell, J., Pendas, A., Teba, F. \& Marquez, M. (2003). Met and unmet needs of schizophrenia patients in Spanish sample. Schizophrenia Bulletin, 29 (2), 201-10. doi: 10.1017/S0033291700000787 
Pillai, R. R, Sahu, K. K., Matthew, V., Hazra, S. Chandran, P. \& Ram, D. (2010). Rehabilitation needs of persons with major mental illness in India. International Journal of Psychosocial Rehabilitation, 14(2), 95-104.

Prafulla, S., Murthy, S. K., \& Ramaprasad, D. (2010). Family Burden and Rehabilitation Needs of Beneficiaries of a Rural Mental Health Camp in a Southern State of India. International Journal of Psychosocial Rehabilitation. 15(2) 5-11.

Raguram, R., Raghu, T. M., Vounatsou, P., \& Weiss, M. G. (2004). Schizophrenia and the cultural epidemiology of stigma in Bangalore, India. The Journal of Nervous and Mental Disease, 192 (11), 734-744.

Ralston, G., Beesley, S., \& Bogue, J. (1998). User's needs and satisfaction with community based mental health service. Psychiatric Bulletin, 22, $473-476$.

Thara, R., Kamath, S., \& Kumar, S. (2003a) Women with schizophrenia and broken marriages - doubly disadvantaged? Part I: Patient Perspective. International Journal of Social Psychiatry, 49, 225-232.

Thara, R., Kamath, S., \& Kumar, S. (2003b) Women with schizophrenia and broken marriages - doubly disadvantaged? Part I: Family Perspective. International Journal of Social Psychiatry, 49, 233 - 240.

Thara, R. \& Srinivasan, T. N. (2000). How stigmatizing is schizophrenia in India. International Journal of Social Psychiatry, 46, 135 - 141.

Winefield, H. R. \& Harvey, E. J. (1994). Needs of family caregivers in chronic schizophrenia. Schizophrenia Bulletin, 20 (3), 557- 567. 